\title{
Environmental Photochemistry of Amino Acids, Peptides and Proteins
}

\author{
Rachel A. Lundeen, Elisabeth M.-L. Janssen, Chiheng Chu, and Kristopher McNeill*
}

\begin{abstract}
Amino acids, peptides and proteins are central building blocks of life and of key importance in the biogeochemistry of aquatic ecosystems. In sunlit surface waters, amino acid-based molecules at different levels of structural organization are susceptible to transformation by both direct photochemical reactions and indirect processes caused by photochemically produced reactive oxygen species (e.g. hydroxyl radical or singlet oxygen). Photochemical transformation processes can thereby affect the availability of these crucial nutrient sources in aquatic ecosystems, inhibit the function of microbial extracellular enzymes, or even promote the degradation of amino acid-based pollutant molecules. In this article, the environmental photochemistry of amino acids, peptides and proteins in aquatic systems is reviewed.
\end{abstract}

Keywords: Amino acids · Environmental fate $\cdot$ Natural organic matter $\cdot$ Photochemistry $\cdot$ Proteins

\section{Introduction}

Nitrogen is an essential element of all living organisms and fixed nitrogen is one of the most limiting nutrients in many ecosystems. ${ }^{[1]}$ In natural waters, amino acids (AAs) are valuable sources of fixed nitrogen for the environmental microbiome, acting as the building blocks for proteins and providing energy for microbial metabolism and growth. AAs and AA-based molecules (e.g. peptides and proteins) are ubiquitous in surface waters, derived from biotic processes including extracellular exudate production (active or passive) by phytoplankton, ${ }^{[2]}$ active release of microbial extracellular enzymes, ${ }^{[3]}$ zooplankton release via grazing, fecal pellet excretion or decay, ${ }^{[4]}$ and viral-induced lysis of autotrophs and heterotrophs (Fig. 1). ${ }^{[5]}$ In addition, AA-based molecules can be introduced into aquatic systems through atmospheric deposition ${ }^{[6]}$ or anthropogenic inputs, such as agricultural runoff or wastewater effluent. ${ }^{[7]}$ Once released into surface waters, AAs and AA-based molecules are susceptible to a variety of environmental fate processes, including bacteria or phytoplankton uptake ${ }^{[8]}$ and abiotic transforma-

\footnotetext{
${ }^{*}$ Correspondence: Prof. Dr. K. McNeill Institute of Biogeochemistry and Pollutant Dynamics ETH Zurich

Universitätstrasse 16

$\mathrm{CH}-8092$ Zurich

Tel.: +4144632 4755

E-mail: kris.mcneill@env.ethz.ch
}

tions, such as photochemical reactions or adsorption (Fig. 1). ${ }^{\text {9] }}$ Yet, comprehensive studies examining the environmental fate of this pool of bioavailable substrates are scarce. There are significant gaps in our understanding of the environmental factors that impact this pool, which are essential for elucidating the roles of AAs and AAbased molecules in global biogeochemical cycles, modeling nutrient fluxes in aquatic ecosystems, ${ }^{[9]}$ and predicting the persistence of AA-based pollutant molecules. ${ }^{[10]}$

A major limitation in examining the environmental fate of AA-based molecules in aquatic environments is that the environmental pool of AA-based molecules is chemically complex and largely uncharacterized. ${ }^{[1 b, 11]}$ Natural waters contain, at any one point in time, a diverse mixture of dissolved free amino acid monomers (DFAAs) and AA-based molecules with different levels of structural organization, ranging from peptides (i.e. primary protein structure) to extracellular enzymes (i.e. tertiary or quaternary protein structure), collectively referred to herein as dissolved combined amino acids (DCAAs; refer to Fig. 1). Yet, this DCAA pool can be extended to include larger protein complexes, such as viruses ${ }^{[5 a]}$ and bacterial membrane porins (outer membrane channel proteins), ${ }^{[12]}$ or could be a complex concoction of AA-based molecules with unknown structural organization indicative of partially denatured enzymes, molecules with unique structural motifs (e.g. branched, cyclic or polycyclic), or AA-based molecules at varying stages of degradation (e.g. par-

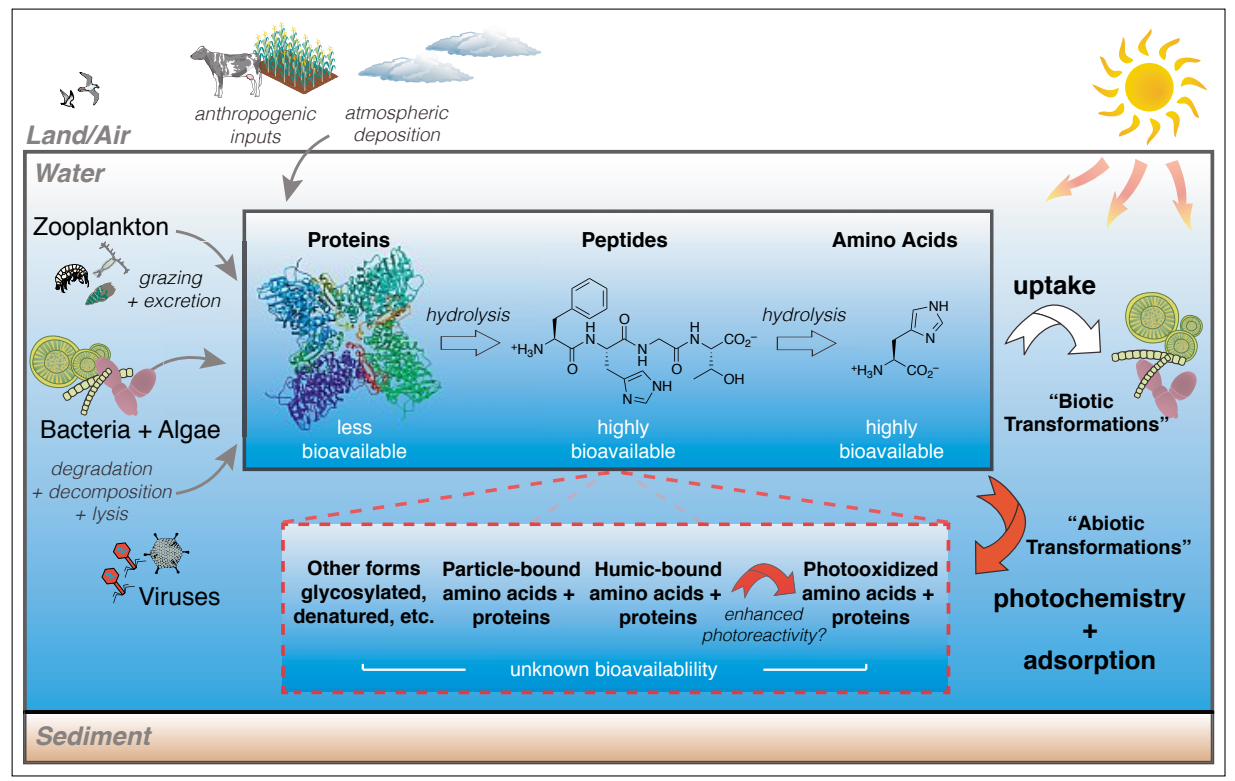

Fig. 1. Schematic representation of some of the sources and sinks of dissolved free amino acids and dissolved combined amino acids (e.g. peptides and proteins) in aquatic systems. 
tially hydrolyzed proteins). The complexity of this pool, therefore, makes it difficult to study the transformation processes governing their environmental fate.

It is well understood that DFAAs, proteins and other DCAAs are important bioavailable nitrogen substrates for marine and freshwater microorganisms. ${ }^{[3 c, 13]}$ Compared to smaller DFAAs that are readily taken up, DCAAs require further degradation to liberate smaller AAs and peptides before they can be assimilated. This process can be facilitated by proteolytic enzymes (e.g. aminopeptidases) that catalyze peptide hydrolysis.[3b] In some instances, photochemical reactions have been shown to release labile AAs or ammonia (i.e. photoammonification). ${ }^{[9,14]}$ However, Keil et $a l .{ }^{[11 \mathrm{a}]}$ predict a broad continuum of DCAA lability ranging from highly labile protein to highly recalcitrant DCAA forms.

There is increasing recognition that microbial utilization of proteins and DCAAs may be affected by abiotic transformations. For example, in sunlit surface waters, photochemical reactions can degrade or impact concentrations of DCAAs, ${ }^{[9]}$ and have been shown to inactivate or inhibit extracellular enzymes (e.g. aminopeptidases or phosphatases), ${ }^{[9,15]}$ which are critical in the microbial acquisition of nutrients from otherwise inaccessible sources.[3a] In another example, protein adsorption to organic matter, clays, or other particles, may inactivate enzymes ${ }^{[16]}$ or preserve these molecules through encapsulation. ${ }^{[17]}$ Currently, it is unknown both to what extent abiotic transformations affect the availability of DFAAs and DCAAs and specifically, what role abiotic transformation processes play in the environmental fate of AA-based molecules.

In this article, we review the environmental photochemistry of AAs and AAbased molecules. We first focus on the photochemical transformations of DFAAs by direct and indirect photochemical reactions under environmentally relevant conditions. We then present recent advances in the study of photochemical transformations of structurally more complex AA-based molecules. This is followed by a discussion of the possible effects on the photochemistry of AAs (free and combined) as the result of their interactions with natural organic matter. Finally, we discuss the outlook and implications of this area of research.

\section{Photochemical Reactions of Dissolved Free Amino Acids (DFAAs)}

In sunlit surface waters, DFAAs and AA-based molecules are susceptible to photochemical transformation. Much of what is known about the photochemical oxidation of AAs stems from photobiology studies relevant to cellular systems. ${ }^{[18]}$ In these systems, intracellularly generated reactive oxygen species (ROS; e.g. singlet oxygen $\left({ }^{1} \mathrm{O}_{2}\right)$, hydroxyl radical $\left({ }^{\circ} \mathrm{OH}\right)$, hydrogen peroxide $\left(\mathrm{H}_{2} \mathrm{O}_{2}\right)$ ) can lead to damage and degradation of biomolecules such as DNA, proteins and lipids. ${ }^{[18]}$ In fact, AAs and proteins are considered the key targets of cellular ROS.[18,19] Thus, reactions of proteinogenic AAs with various ROS have been extensively studied and most bimolecular rate constants are known, some of which are given in Fig. 2. ${ }^{[20]}$ In the following sections, key studies from both environmental photochemistry and photobiology are summarized; these findings provide an overview of the current understanding of the photochemical behavior of AA-based molecules in natural waters.

An understanding of the photochemistry of DFAAs is important not only for assessing the environmental fate of free AAs, but also provides a foundation for studying the photochemical transformation of DCAAs. From photobiology studies, it is well understood that ROS react preferentially with the side-chain moieties of the
AAs tryptophan, tyrosine, histidine, cysteine and methionine, collectively referred to as photooxidizable AAs (Fig. 2). Recently, Pattison et al. ${ }^{[21]}$ extensively reviewed the mechanistic pathways of the photooxidation of AAs with various ROS. Under environmentally relevant conditions, Boreen et al. ${ }^{[22]}$ showed that among the 18 of 20 proteinogenic AAs assessed (cysteine and proline were not examined for analytical reasons), the AAs tryptophan, tyrosine, histidine and methionine are susceptible to photochemical degradation both by direct and indirect processes, which are caused by ROS and excited triplet states of natural organic matter. ${ }^{[22]}$

\section{Direct Photochemical Reactions}

Direct photochemical degradation requires an AA moiety (i.e. chromophore) that is capable of absorbing light of the solar spectrum. A substantial fraction of the solar UV radiation is absorbed by atmospheric ozone, with only a small portion of the UVB light $(\lambda=280-320 \mathrm{~nm})$ reaching surface waters. In comparison, there is relatively more UVA light $(\lambda=320-400$ $\mathrm{nm})$ and visible light $(\lambda>400 \mathrm{~nm})$. Thus,

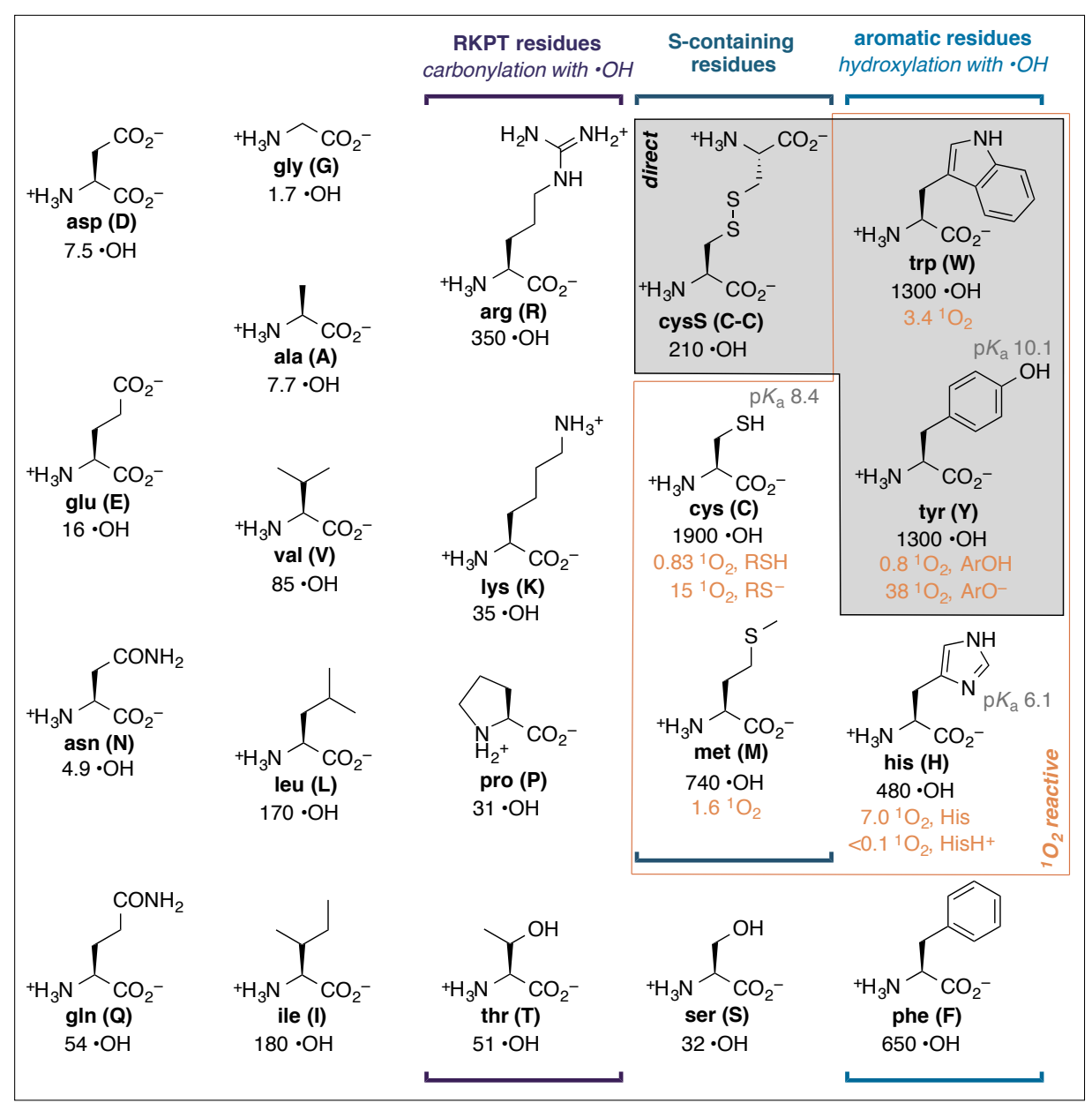

Fig. 2. An overview of the 20 proteinogenic amino acids and cystine, the disulfide of cysteine, and their reactivity by direct and indirect photochemical processes under environmentally relevant conditions ( $\mathrm{pH} 6-9 ; \lambda>280 \mathrm{~nm})$. Known bimolecular reaction rate constants of amino acids with hydroxyl radical $\left({ }^{\circ} \mathrm{OH}\right)$ and singlet oxygen $\left({ }^{1} \mathrm{O}_{2}\right)$ are shown. ${ }^{[20]}$ All reaction rate constants are given in $10^{7} \mathrm{M}^{-1} \mathrm{~s}^{-1}$ 
for the proteinogenic AAs, only tryptophan and tyrosine are susceptible to direct photolysis in sunlight. ${ }^{[22,23]}$ The direct photochemistry of tyrosine is $\mathrm{pH}$ dependent ( $\mathrm{p} K_{\mathrm{a}}$ of tyrosine side-chain is 10.1). In its protonated form, tyrosine has very little spectral overlap with the solar spectrum; however, the phenolate form has substantial overlap. Hence, direct photochemical reaction for tyrosine may be significant only in more alkaline waters. Cystine, the disulfide of cysteine, shows a very weak absorbance in the UVB region and could potentially undergo direct photochemical transformation, but this has not been documented under environmentally relevant conditions. Tryptophan shows the greatest spectral overlap with the solar spectrum and Janssen et al. ${ }^{[23]}$ observed significant direct photochemical degradation of tryptophan in natural waters.

\section{Indirect Photochemical Reactions}

In natural waters, chromophoric dissolved organic matter (CDOM) is an important constituent that absorbs solar radiation and ROS are continuously produced upon CDOM absorption of sunlight. [24] Consequently, in aquatic environments photooxidizable AAs are susceptible to degradation by photochemically generated ROS. In particular, hydroxyl radical $\left({ }^{\circ} \mathrm{OH}\right)$, singlet oxygen $\left({ }^{1} \mathrm{O}_{2}\right)$, and hydrogen peroxide $\left(\mathrm{H}_{2} \mathrm{O}_{2}\right)$, as well as triplet excited CDOM molecules ( $\left.{ }^{3} \mathrm{CDOM}\right)$ are important oxidants, which are commonly found at picomolar to micromolar concentrations in environmental systems. Techniques have been developed to measure steady-state concentrations of some ROS, but their short lifetimes and fast reaction rates make quantification of ROS challenging. ${ }^{[25]}$ In the following section, the relevance of these reactive species in aquatic systems and their reactions with photooxidizable AAs are summarized.

\section{Hydroxyl Radicals}

Hydroxyl radicals $\left({ }^{\circ} \mathrm{OH}\right)$ are formed in the presence of oxygen and photochemical reactions of CDOM, nitrate, and nitrite or by Fenton chemistry. Measured lifetimes of $\cdot \mathrm{OH}$ range from $0.2-40 \mu \mathrm{sec}^{[20 \mathrm{a}]}$ and lifetimes are highly dependent on the concentration of ${ }^{\bullet} \mathrm{OH}$ quenchers present in the aquatic system, mainly represented by DOM. Steady-state concentrations of ${ }^{\circ} \mathrm{OH}$ are low, ranging from $10^{-15}$ to $10^{-17} \mathrm{M},{ }^{[26]}$ and are rather stable (i.e. at DOM concentrations greater than $5 \mathrm{mg}$ carbon $\left.\mathrm{L}^{-1}\right)^{[27]}$ because (i) DOM represents both the major source and sink for ${ }^{\circ} \mathrm{OH}$, (ii) ${ }^{\circ} \mathrm{OH}$ reacts at fast rates, and (iii) ${ }^{\circ} \mathrm{OH}$ reacts relatively unselectively with many substrates. Since - $\mathrm{OH}$ is such a potent oxidant, all proteinogenic AAs are susceptible to reactions with ${ }^{\circ} \mathrm{OH}$; the bimolecular reaction rate constants of AAs with ${ }^{\circ} \mathrm{OH}$ range from 1.7 $\times 10^{7} \mathrm{M}^{-1} \mathrm{~s}^{-1}$ (glycine) to $1.3 \times 10^{10} \mathrm{M}^{-1} \mathrm{~s}^{-1}$ (tryptophan and tyrosine) (Fig. 2).

For several AAs, the mechanisms of reaction with ${ }^{\circ} \mathrm{OH}$ are known. For instance, the side chain of arginine, lysine, proline and threonine (i.e. RKPT residues; Fig. 2) are known to undergo carbonylation upon reaction with ${ }^{\circ} \mathrm{OH}$; in fact, this is a wellknown mechanism of oxidative protein damage in cellular systems. ${ }^{[28]}$ The aromatic side-chains of the AAs tryptophan, tyrosine, histidine, and phenylalanine react with ${ }^{\circ} \mathrm{OH}$ by addition reactions resulting in hydroxylation of the aromatic ring. Considering the range of environmental - OH concentrations, one can calculate the environmental half-lives of the fastest reacting AAs, tryptophan and tyrosine, to range from 14 hours to 60 days in sunlit surface waters, for reactions with ${ }^{\circ} \mathrm{OH}$ only.

\section{Singlet Oxygen}

Singlet oxygen $\left({ }^{1} \mathrm{O}_{2}\right)$ is formed by energy transfer from an excited triplet sensitizer to molecular oxygen. For example, in sunlit surface waters, reactions of ${ }^{3} \mathrm{CDOM}$ with oxygen can generate ${ }^{1} \mathrm{O}_{2}$. As the energy required to excite oxygen from its triplet ground state to its first excited singlet state is low $\left(22.5 \mathrm{kcal} \mathrm{mol}^{-1}\right.$ from $\mathrm{T}_{0}$ to $\left.S_{1}\right),{ }^{[29]}$ most triplet sensitizers are energetic enough to produce ${ }^{1} \mathrm{O}_{2}$ at diffusioncontrolled rates. The lifetime of ${ }^{1} \mathrm{O}_{2}$ in pure water is $4 \mu \mathrm{sec}^{[30]}$ and is typically lower in the aquatic environment depending on the concentrations of quenching molecules. Steady-state concentrations of ${ }^{1} \mathrm{O}_{2}$ typically range from $10^{-12}$ to $10^{-14} \mathrm{M}$ in surface waters. ${ }^{[31]}$ Despite higher steady-state concentrations of ${ }^{1} \mathrm{O}_{2}$ compared to ${ }^{\circ} \mathrm{OH}$, the reactivity of ${ }^{1} \mathrm{O}_{2}$ is far more selective. Thus, fewer AAs (i.e. 5 out of 20 proteinogenic AAs) react with ${ }^{1} \mathrm{O}_{2}$ and the bimolecular rate constants are one to three orders of magnitude lower with ${ }^{1} \mathrm{O}_{2}$ than with ${ }^{\bullet} \mathrm{OH}$ (Fig. 2). The mechanisms of ${ }^{1} \mathrm{O}_{2}$ reactions with these photooxidizable AAs have been described in the literature. ${ }^{[32]}$

In aquatic systems, photochemically produced ${ }^{1} \mathrm{O}_{2}$ plays a major role in the degradation of histidine and to a lesser extent for tryptophan and tyrosine. ${ }^{[22]}$ Boreen $e t$ $a l .{ }^{[22]}$ showed that the degradation of histidine may be attributed solely to reactions with ${ }^{1} \mathrm{O}_{2}$ (i.e. no significant reactivity with ${ }^{3} \mathrm{CDOM}$ or $\left.{ }^{\circ} \mathrm{OH}\right)$ in natural waters. In addition, histidine has the highest reactivity with ${ }^{1} \mathrm{O}_{2}$ at circumneutral $\mathrm{pH}$ values compared to other photooxidizable residues (i.e. with a reaction rate constant on the order of $7 \times 10^{7} \mathrm{M}^{-1} \mathrm{~s}^{-1}$ ); thus, the half-life of histidine based on reaction with ${ }^{1} \mathrm{O}_{2}$ would be much shorter, ranging from three hours to 12 days, than estimates of reactions with $\cdot \mathrm{OH}$ (vide supra).

\section{Hydrogen Peroxide}

Hydrogen peroxide $\left(\mathrm{H}_{2} \mathrm{O}_{2}\right)$ is considered a tertiary ROS because the formation of $\mathrm{H}_{2} \mathrm{O}_{2}$ requires first, the reduction of oxygen to superoxide $\left(\mathrm{O}_{2}^{--}\right)$by a photo-excited sensitizer (e.g. $\left.{ }^{3} \mathrm{CDOM}\right)$ and second, the dismutation of $\mathrm{O}_{2}{ }^{--}$to $\mathrm{H}_{2} \mathrm{O}_{2} \cdot{ }^{[33]}$ Hydrogen peroxide is ubiquitous in surface waters, which is due to its extremely long lifetime (hours or days), ${ }^{[34]}$ and $\mathrm{H}_{2} \mathrm{O}_{2}$ concentrations range between $10^{-6}$ and $10^{-11} \mathrm{M} .{ }^{[35]}$ Even though $\mathrm{H}_{2} \mathrm{O}_{2}$ is present at high concentrations in the aquatic environment, its reactivity with AAs is very selective and the reaction rates are low compared to ${ }^{1} \mathrm{O}_{2}$ or ${ }^{\bullet} \mathrm{OH}$. In natural waters, it is expected that $\mathrm{H}_{2} \mathrm{O}_{2}$ may be important in the degradation of sulfur-containing AAs (refer to Fig. 2), such as cysteine and methionine. ${ }^{[21,22]}$

\section{Triplet DOM and DOM as an \\ Antioxidant}

Besides being a source of ROS in surface waters, ${ }^{3} \mathrm{CDOM}$ can be considered a reactive species in its own right. Triplet CDOM is a mixture of many species, which makes its quantification and assessment of its reactivity more challenging. Triplet CDOM has been shown to participate in both electron transfer oxidation ${ }^{[36]}$ and energy transfer reactions. ${ }^{[37]}$ The current literature suggests that the AAs tryptophan, tyrosine, histidine and methionine can undergo oxidation by ${ }^{3}$ CDOM. ${ }^{[22,23,38]}$ Remucal and McNeill[39] have shown that the reaction rate constants of AAs with triplet flavins ranged over one order of magnitude with decreasing rates from tryptophan to tyrosine, methionine, and histidine. Tryptophan can be directly oxidized by reaction with ${ }^{3} \mathrm{CDOM}$ and degradation by ${ }^{3} \mathrm{CDOM}$ represents the dominant pathway (approximately 55\%) of its photochemical degradation in the aquatic environment. ${ }^{[22,23]}$

Aside from its photosensitizing properties, DOM also plays an opposing role, slowing photooxidation. Janssen et al. ${ }^{[23]}$ have recently shown that DOM can quench the photooxidation of tryptophan. Both direct photochemical reactions and reactions with ${ }^{3} \mathrm{CDOM}$ form tryptophan radical cation intermediates, which can be converted back to tryptophan through suitable electron or hydrogen atom donors, for example by redox-active components of DOM.[23]

\section{Relative Rates and Pathways of Photooxidation of DFAAs in the Water Column}

The photochemical reaction rates of photooxidizable AAs with ROS are typically measured under conditions of full sunlight exposure (or simulated sunlight exposure in the laboratory). Yet, these conditions are only representative of the uppermost portion of the water column (i.e. 
top few centimeters). In fact, the relative importance of direct and indirect photochemical processes changes with water depth. As sunlight penetrates into the water column, natural water constituents (i.e. organic matter, algae or particles) can absorb or effectively screen sunlight and thereby alter the sunlight spectrum at varying water depths (Fig. 3 inset). The data in Fig. 3 illustrate the dependence of direct and indirect photochemical degradation pathways for tryptophan as a function of depth in the photic zone. Natural organic matter screens sunlight across the solar spectrum and results in approximately $50 \%$ and $5 \%$ of the total irradiance penetrating $10 \mathrm{~cm}$ and $100 \mathrm{~cm}$ into the water column, respectively (Fig. 3). The UVB component of the solar spectrum penetrates to approximately $20 \mathrm{~cm}$ under these simulated conditions and accordingly, the overall photochemical degradation rates of tryptophan decrease. Thus, the overall effect of AA photochemi-

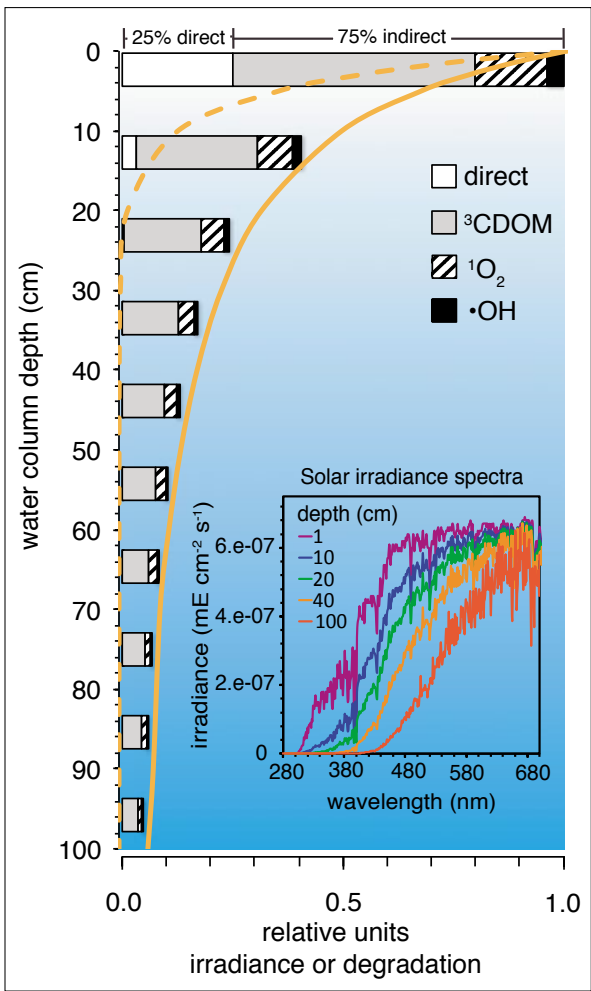

Fig. 3. An example of major photochemical reaction pathways involved in the degradation of the AA tryptophan in aquatic environments, presented as a function of depth in the water column $(0-100 \mathrm{~cm})$. Also, the relative penetration of sunlight irradiation $(280-700 \mathrm{~nm})$ and the UVB component of the solar spectrum (280-320 nm) throughout the water column are presented (yellow solid and dashed lines, respectively); values were calculated using the absorption spectrum for Suwannee River Fulvic Acid at $5 \mathrm{mg}$ carbon $\mathrm{L}^{-1}$. The relative contribution of direct and indirect photochemical degradation pathways (i.e. ${ }^{3} \mathrm{CDOM}, \cdot \mathrm{OH}$, and ${ }^{1} \mathrm{O}_{2}$ ) were calculated for the case of tryptophan (bar graph). The figure inset shows the effect of wavelength-dependent screening on the sunlight spectrum at various water depths. cal transformations (direct and indirect) decreases into the water column and may become less competitive fate processes relative to biodegradation.

\section{Photochemistry of Peptides and Proteins}

It is well established that several DFAAs are susceptible to photooxidation by ROS (vide supra). Yet, in both cellular and environmental systems, the photooxidation kinetics of AA residues within peptides and proteins has received much less attention. The susceptibility of AA residues to photooxidation in a peptide or protein is highly dependent on protein structure and their reaction rates are poorly predicted based on the rate constants for DFAAs. Unique protein structure environments can result in variability in the chemical reactivity and mechanism of oxidation of an AA residue. ${ }^{[40]}$ This variability seems to be mainly due to two factors: $(i)$ steric hindrance from neighboring residues in the primary protein structure, and (ii) the three-dimensional location of the residues in the folded higher-order structure (i.e. tertiary or quaternary protein structure).

Previous studies have shown that several individual AA monomers (i.e. DFAA) are degraded by photogenerated ROS in natural waters, with ${ }^{1} \mathrm{O}$ being an important oxidant in many cases. ${ }^{222,23]} \mathrm{A}$ recent study by Lundeen and $\mathrm{McNeill[41]}$ quantified the range of ${ }^{1} \mathrm{O}_{2}$ photoreactivity of photooxidizable $\mathrm{AA}$ residues, primarily histidine residues, within the context of well-defined peptides and an intact protein. To assess the photochemical reactivity of AA residues in higher order protein structures, proteomic techniques were adapted to follow the photooxidation of individual residues within a protein. ${ }^{[41]}$

Lundeen and $\mathrm{McNeill[41]}$ examined the dependence of ${ }^{1} \mathrm{O}_{2}$ reaction rate constants $\left(k_{r x n}\right)$ on residue accessibility in the intact protein, glyceraldehyde-3-phosphate dehydrogenase (GAPDH). In these studies, GAPDH was an ideal representative protein owing to its well-characterized crystal structure. GAPDH crystal structure data were important in calculations of ${ }^{1} \mathrm{O}_{2}$ accessible surface areas $\left({ }^{1} \mathrm{O}_{2}\right.$-ASA) of histidine residues (Fig. 4). The ${ }^{1} \mathrm{O}_{2}$-ASA values of histidine residues spanned the entire range of accessibilities within the three-dimensional structure of GAPDH and provided an ideal structural framework to examine the effect of accessibility on ${ }^{1} \mathrm{O}_{2} k_{r x n}$ values.

The photochemical reactivity of histidine residues in GAPDH were found to span a four-fold range of ${ }^{1} \mathrm{O}_{2} k_{r x n}$ values (Fig. 4). Histidine residues located on the surface of GAPDH (i.e. $\mathrm{H} 54{ }^{1} \mathrm{O}_{2}$-ASA = $138 \AA^{2}$ ), were found to be more susceptible to oxidation by ${ }^{1} \mathrm{O}_{2}$ than histidine residues buried in the interior of the folded protein (e.g. $\mathrm{H} 108{ }^{1} \mathrm{O}_{2}-\mathrm{ASA}=0.21 \AA^{2}$ ). These differences in ${ }^{1} \mathrm{O}_{2} k_{r r n}$ values were linearly correlated with calculated histidine ${ }^{1} \mathrm{O}_{2}$ ASA values (Fig. 4).[41]

In addition, the effect of primary sequence on ${ }^{1} \mathrm{O}_{2}$ reactivity was found to be small.[41] This was established by examin-

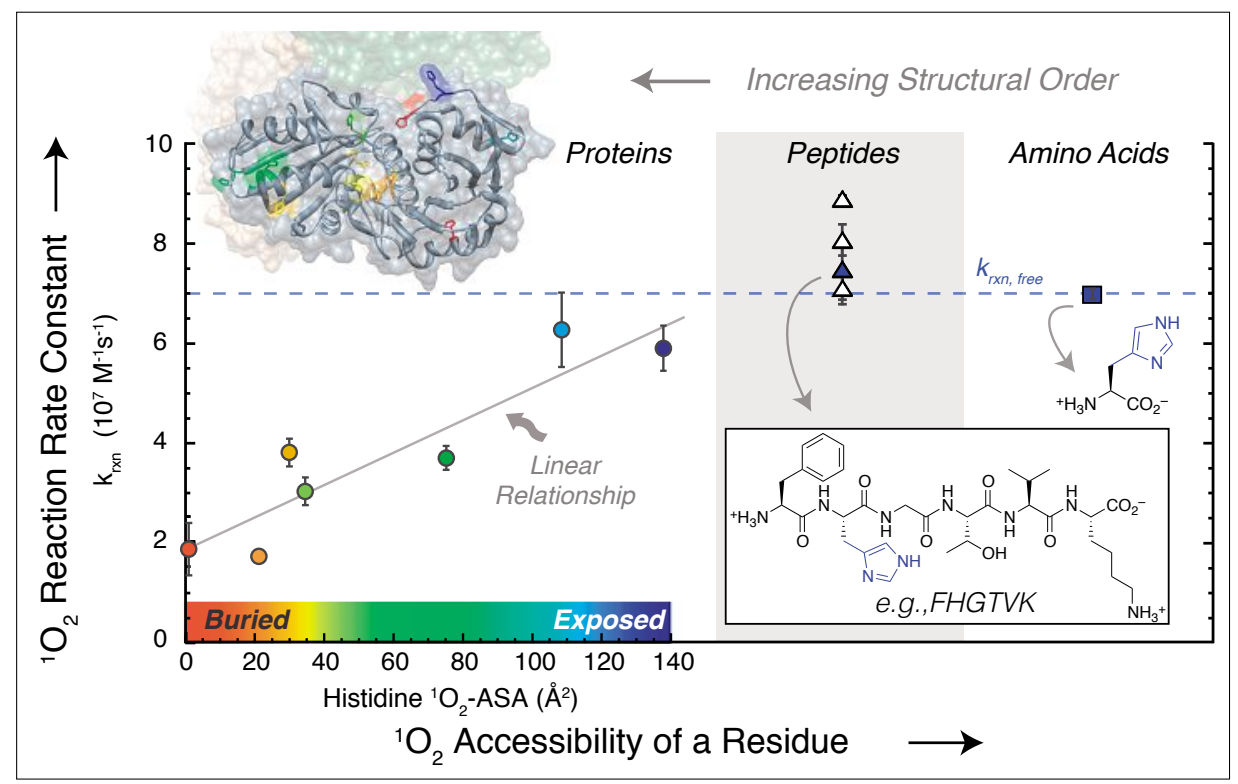

Fig. 4. Reaction rate constants $\left(k_{r x n} ; 10^{7} \mathrm{M}^{-1} \mathrm{~s}^{-1}\right)$ for ${ }^{1} \mathrm{O}_{2}$ reaction with histidine in the context of increasing structural order ${ }^{[4]]}$ Protein $k_{r \times n}$ values are indicative of individual histidine residues within the protein GAPDH. Calculated values of histidine ${ }^{1} \mathrm{O}_{2}$ accessible surface areas $\left({ }^{1} \mathrm{O}_{2}\right.$-ASA) from GAPDH crystal structure data are shown (color spectrum; ranging from buried to exposed residues). Peptide $k_{r \times n}$ values are shown for short unstructured peptides containing only one histidine residue, e.g., phe-his-gly-thr-val-lys (FHGTVK). The ${ }^{1} \mathrm{O}_{2} k_{r \times n}$ of the free histidine monomer sets an approximate upper limit of $k_{r \times n}$ (dashed blue line). Reprinted (adapted) with permission from Lundeen and McNeill. ${ }^{[4]]}$ Copyright 2013 American Chemical Society. 
ing the reactivity of histidine residues in short, unstructured peptides (i.e. peptides were composed of six to seven AA residues with no secondary protein structure). The data showed that ${ }^{1} \mathrm{O}_{2} k_{r x n}$ for histidine residues in such peptides were similar to one another and also to that of the free histidine monomer (refer to Fig. 4). This agreement of $k_{r x n}$ indicates that the primary protein structure has only a minor influence on the ${ }^{1} \mathrm{O}_{2}$ reactivity of histidine residues.

For higher-order protein structures, the observed ${ }^{1} \mathrm{O}_{2}$ reactivity differences of histidine residues have broad implications for predicting the photochemical transformations of AA-based molecules in sunlit surface waters. For freely dissolved and unstructured AA-based molecules (e.g. short peptides), reaction rates can be adequately predicted using the $k_{r x n}$ values for free histidine monomers. However, the indirect photochemical transformation rates of AA-based molecules with higher-order protein structures cannot be predicted simply using the reaction rates of free AA residues; rather, they require the use of location-specific rate constants. These observations may be useful in assessing the role of photochemistry in the degradation of DCAAs over competing processes of microbial uptake or biodegradation.

\section{Sorption of AAs, Peptides and Proteins to Organic Matter and Its Effect on Their Photochemical Fate}

Natural organic matter, which has been described above as an important photosensitizer and quencher, plays an additional role as a sorbent for AA-based molecules. The factors controlling the sorption or binding of AA-based molecules to natural organic matter have been established in several studies; $[17 \mathrm{~d}, \mathrm{e}, 42]$ however, the mechanism of binding between AAs and natural organic matter is still an active area of research. While binding of DFAAs and DCAAs to natural organic matter certainly has implications with respect to the transport and bioavailability of AAs, herein only the potential of sorption to alter AA photochemistry is briefly discussed.

From a photochemical standpoint, there are two major characteristics of natural organic matter that may influence the photochemistry of bound AAs. First, natural organic matter contains species that can act as excited state quenchers and ROS scavengers, and thus natural organic matter can protect bound AAs from photochemical damage. Second, natural organic matter contains sensitizers that generate ROS, and thus AAs bound to organic matter could experience high local ROS concentrations ${ }^{[43]}$ that enhance rates of AA photooxidation. In one study, Kohn et al. ${ }^{[44]}$ observed that association of the ganic matter resulted in faster rates of ${ }^{1} \mathrm{O}_{2}$ inactivation compared to ${ }^{1} \mathrm{O}_{2}$ inactivation rates for freely dissolved MS2. Though it is increasingly evident that AA-organic matter complexes are important in altering the photochemistry of AAs, the extent to which these interactions impact the rates of photochemical transformations of AAbased molecules remains to be seen.

\section{Environmental Implications}

Amino acid-based molecules play numerous important roles in environmental systems, acting as valuable substrates for heterotrophic bacteria, as functional extracellular enzymes that are important in nutrient acquisition (e.g. alkaline phosphatase), or even as contaminants that can endanger human health (e.g. naturally occurring toxins like microcystins). Photochemical processes that oxidize AAs and alter their structures are likely to disrupt these roles in the environment. Examining Fig. 2, one might have the impression that the effects of photochemistry are fairly limited, with so few of the AA monomers being reactive toward direct photochemical transformations or reaction with most ROS. However, it is important to consider the 'value' of the AAs that are the primary targets of photooxidation.

The high value of the photooxidizable AAs can be visualized by examining Fig. 5 , which shows the 20 proteinogenic AAs plotted in two dimensions, each dimension corresponding to a measure of AA value. On the $x$-axis, free energies are reported for virus, bacteriophage MS2, with natural or-

the synthesis of each AA from $\mathrm{CO}_{2}, \mathrm{NH}_{4}^{+}$, $\mathrm{H}_{2} \mathrm{~S}$ and $\mathrm{H}_{2}\left(\Delta \mathrm{G}_{\mathrm{r}}\right.$ were calculated for surface seawater conditions) ${ }^{[45]}$ and provide a direct measure of the thermodynamic 'expense' of each AA. On the $y$-axis, the abundance of each AA as a fraction of the total AA pool is plotted. Amino acid abundances in three pools are considered: cellular proteins ${ }^{[46]}$ and DFAAs and DCAAs reported in aquatic environments. ${ }^{[47]}$ Here, rare AAs are construed as more valuable. Indeed, a general inverse relationship between abundance and thermodynamic cost is seen in this data. Four of the five photooxidizable AAs fall into the lower right quadrant of the graph, corresponding to rare and expensive AAs. The fifth AA, methionine, might not be considered 'expensive' by this thermodynamic measure, but it is certainly rare. Fig. 5 also shows that as one moves from the cell to the aquatic environment, there is a general trend of the rare AAs becoming rarer and the abundant ones becoming enriched.

Whether the depletion of rare, valuable AAs in the aquatic environment is more reflective of their selective photochemical removal or their selective uptake by microorganisms is an open question. Nevertheless, it is clear that photooxidation selectively targets some of the most valuable AAs. A similar conclusion can be reached if one considers not only total abundance but also abundance in active sites of enzymes. Such an analysis concluded that histidine and cysteine were the two most overrepresented AAs in enzyme active sites, indicating that photochemistry has a high potential to inactivate enzymes through oxidation of these catalytic residues. ${ }^{[48]}$

The knowledge of environmental pho-

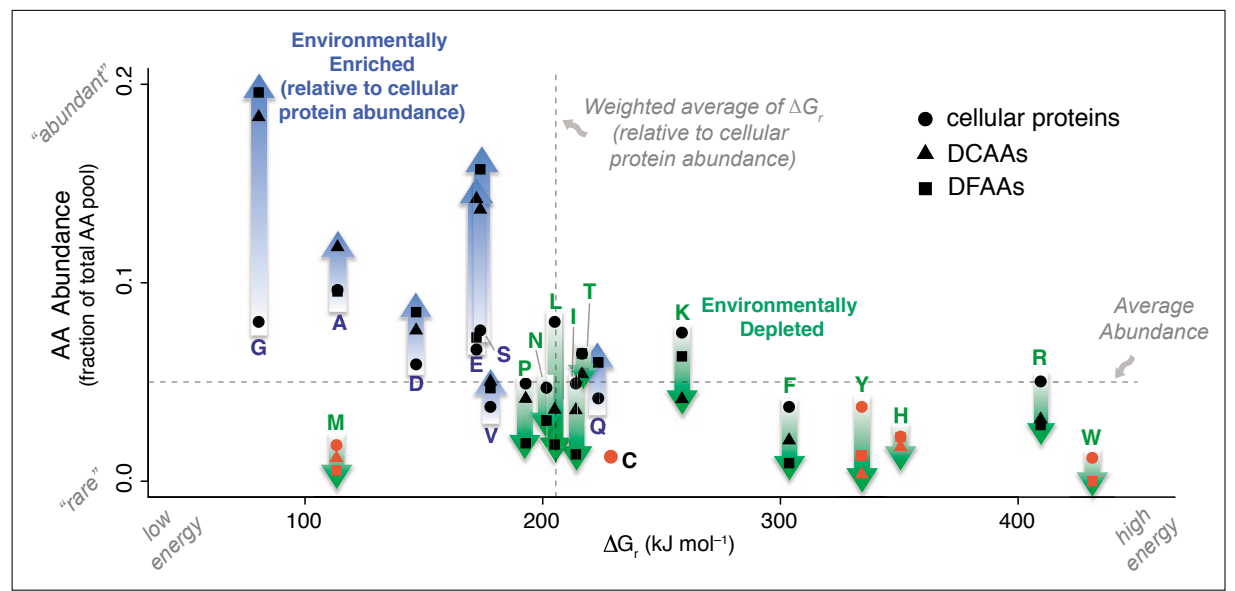

Fig. 5. Abundances of proteinogenic amino acids versus the energy required for $A A$ synthesis reactions $\left(\Delta \mathrm{G}_{\mathrm{r}} ; \mathrm{kJ} \mathrm{mol}^{-1}\right) \cdot{ }^{[45]}$ The $\Delta \mathrm{G}_{\mathrm{r}}$ values are given for the hypothetical synthesis of each amino acid from $\mathrm{CO}_{2}, \mathrm{NH}_{4}^{+}, \mathrm{H}_{2} \mathrm{~S}$ and $\mathrm{H}_{2}$ under surface seawater conditions. ${ }^{[45]}$ The AA abundances are given for cellular proteins ${ }^{[46]}$ and compared to DFAAs and DCAAs reported in aquatic environments. ${ }^{[47]} A A$ abundances were calculated as a fraction of the total proteinogenic $A A$ pool. Photooxidizable AAs are shown in red; however, environmental abundances of cysteine were excluded due to a lack of data. Arrows indicate qualitative trends in environmental depletion (green; downward trend) or environmental enrichment (blue; upward trend) of AAs in natural waters relative to their abundance in cellular proteins. Average abundance and weighted average of $\Delta G_{r}$ relative on AA abundance in cellular proteins are plotted for comparison (dotted lines). 
tochemical transformations of DFAAs led the way to examine the photooxidation kinetics of AA residues in structurally more complex DCAAs. More fundamental studies are needed to investigate the effects of sorption to photochemically active organic matter on abiotic transformation processes of AA-based molecules. Beyond photochemical mechanisms, the extent to which photochemical transformations affect the availability of DFAAs and DCAAs in sunlit ecosystems remains to be investigated. In the future, an integrative systems analysis is needed to $(i)$ compare the role of photochemical transformation in the aquatic ecosystem for availability of nutrients and AA-based substrates, and (ii) assess under which conditions photochemical transformation is competitive with other environmental fate processes (e.g. biological uptake, sorption and sedimentation).

\section{Acknowledgements}

We gratefully acknowledge financial support from the Swiss National Science Foundation (Project number 200021-138008).

Received: August 21, 2014

[1] a) N. Gruber, J. N. Galloway, Nature 2008, 451, 293 ; b) L. I. Aluwihare, D. J. Repeta, S. Pantoja, C. G. Johnson, Science 2005, 308, 1007; c) A. C. Redfield, Am. Sci. 1958, 46, 205.

[2] D. A. Bronk, P. M. Gilbert, B. B. Ward, Science 1994, 265, 1843.

[3] a) C. Arnosti, Annu. Rev. Mar. Sci. 2011, 3, 401; b) R. J. Chróst, in 'Microbial Enzymes in Aquatic Environments', Ed. R. J. Chróst, Springer: New York, 1991; c) N. O. G. Jorgensen, N. Kroer, R. B. Coffin, X. H. Yang, C. Lee, Mar. Ecol. Prog. Ser. 1993, 98, 135.

[4] W. Lampert, Limnol. Oceanogr. 1978, 23, 831.

[5] a) J. A. Fuhrman, Nature 1999, 399, 541; b) M. Middelboe, N. O. G. Jorgensen, J. Mar. Biol. Ass. U.K. 2006, 86, 605.

[6] a) S. P. Seitzinger, R. W. Sanders, Limnol. Oceanogr. 1999, 44, 721; b) M. Mandalakis, M. Apostolaki, T. Tziaras, P. Polymenakou, E. G. Stephanou, Atmos. Environ. 2011, 45, 1003; c) S. Cornell, A. Randell, T. Jickells, Nature 1995, $376,243$.

[7] a) D. A. Bronk, Q. N. Roberts, M. P. Sanderson, E. A. Canuel, P. G. Hatcher, R. Mesfioui, K. C. Filippino, M. R. Mulholland, N. G. Love, Environ. Sci. Technol. 2010, 44, 5830; b) E. Pehlivanoglu-Mantas, D. L. Sedlak, Water Res. 2008, 42, 3890; c) E. Pehlivanoglu-Mantas, D. L. Sedlak, Crit. Rev. Env. Sci. Tec. 2006, 36, 261.

[8] a) T. Berman, D. A. Bronk, Aquat. Microb. Ecol. 2003, 31, 279; b) D. A. Bronk, in 'Biogeochemistry of Marine Dissolved Organic Matter', Ed. D. A. Hansell, C. A. Carlson, Academic Press, San Diego, 2002; c) D. A. Bronk, J. H. See, P. Bradley, L. Killberg, Biogeosciences 2007, 4, 283.

[9] K. Mopper, D. J. Kieber, in 'Biogeochemistry of Marine Dissolved Organic Matter', Ed. D. A. Hansell, C. A. Carlson, Academic Press, San Diego, 2002.

[10] a) Literature review of contaminants in livestock and poultry manure and implications for water quality, United States Environmental Protection Agency: Washington, DC, 2013; b) R. P. Schwarzenbach, B. I. Escher, K. Fenner,
T. B. Hofstetter, C. A. Johnson, U. von Gunten, B. Wehrli, Science 2006, 313, 1072; c) K. R. Wigginton, L. Menin, J. P. Montoya, T. Kohn, Environ. Sci. Technol. 2010, 44, 5437.

[11] a) R. G. Keil, D. L. Kirchman, Limnol. Oceanogr. 1993, 38, 1256; b) M. McCarthy, T. Pratum, J. Hedges, R. Benner, Nature 1997, 390, 150.

[12] a) N. Yamada, E. Tanoue, Limnol. Oceanogr. 2003, 48, 1037; b) E. Tanoue, M. Ishii, T. Midorikawa, Limnol. Oceanogr. 1996, 41, 1334; c) E. Tanoue, S. Nishiyama, M. Kamo, A. Tsugita, Geochim. Cosmochim. Acta 1995, 59, 2643.

[13] a) J. T. Hollibaugh, F. Azam, Limnol. Oceanogr. 1983, 28, 1104; b) R. B. Coffin, Limnol. Oceanogr. 1989, 34, 531; c) B. Rosenstock, M. Simon, Limnol. Oceanogr. 1993, 38, 1521; d) R. G. Keil, D. L. Kirchman, Mar. Ecol. Prog. Ser. 1991, 73, 1; e) M. Middelboe, N. H. Borch, D. L. Kirchman, Mar. Ecol. Prog. Ser. 1995, 128, 109.

[14] a) K. L. Bushaw, R. G. Zepp, M. A. Tarr, D. Schulz Jander, R. A. Bourbonniere, R. E. Hodson, W. L. Miller, D. A. Bronk, M A. Moran, Nature 1996, 381, 404; b) K. L. Bushaw-Newton, M. A. Moran, Aquat. Microb. Ecol. 1999, 18, 285; c) A. V. Vähätalo, R. G. Zepp, Environ. Sci. Technol. 2005, 39, 6985.

[15] a) N. M. Scully, L. J. Tranvik, W. J. Cooper, Limnol. Oceanogr. 2003, 48, 1818; b) M. J. Boavida, R. G. Wetzel, Freshwater Biol. 1998, $40,285$.

[16] a) Y. Li, W. Tan, L. K. Koopal, M. Wang, F. Liu, W. Norde, Environ. Sci. Technol. 2013, 47, $5050 ;$ b) T. Tietjen, R. G. Wetzel, Aquat. Ecol. 2003, 37, 331 .

[17] a) J. I. Hedges, J. A. Baldock, Y. Gelinas, C. Lee, M. Peterson, S. G. Wakeham, Nature 2001, 409, 801; b) H. Knicker, P. G. Hatcher, Naturwissenschaften 1997, 84, 231; c) T. Nagata, D. L. Kirchman, Mar. Ecol. Prog. Ser. 1996, 132, 241; d) R. T. Nguyen, H. R. Harvey, Geochim. Cosmochim. Acta 2001, 65, 1467; e) J. E. Tomaszewski, R. P. Schwarzenbach, M. Sander, Environ. Sci. Technol. 2011, 45 , 6003; f) W. F. Tan, L. K. Koopal, L. P. Weng, W. H. van Riemsdijk, W. Norde, Geochim. Cosmochim. Acta 2008, 72, 2090; g) X. Zang, J. D. H. van Heemst, K. J. Dria, P. G. Hatcher, Org. Geochem. 2000, 31, 679.

[18] M. J. Davies, Biochim. Biophys. Acta Proteins Proteomics 2005, 1703, 93.

[19] M. J. Davies, Biochem. Biophys. Res. Commun. 2003, 305, 761.

[20] a) G. V. Buxton, C. L. Greenstock, W. P. Helman, J. Phys. Chem. Ref. Data 1988, 17, 513; b) I. B. C. Matheson, J. Lee, Photochem. Photobiol. 1979, 29, 879; c) F. Wilkinson, W. P. Helman, A. B. Ross, J. Phys. Chem. Ref. Data 1995, 24, 663; d) T. P. A. Devasagayam, A. R. Sundquist, P. Di Mascio, S. Kaiser, H. Sies, J. Photochem. Photobiol., B 1991, 9, 105; e) M. Rougee, R. V. Bensasson, E. J. Land, R. Pariente, Photochem. Photobiol. 1988, 47, 485.

[21] D. I. Pattison, A. S. Rahmanto, M. J. Davies, Photochem. Photobiol. Sci. 2012, 11, 38.

[22] A. L. Boreen, B. L. Edhlund, J. B. Cotner, K. McNeill, Environ. Sci. Technol. 2008, 42, 5492.

[23] E. M. L. Janssen, P. R. Erickson, K. McNeill, Environ. Sci. Technol. 2014, 48, 4916.

[24] N. V. Blough, R. G. Zepp, Struct. Energ. React. Chem. Ser. 1995, 2, 280.

[25] J. M. Burns, W. J. Cooper, J. L. Ferry, D. W. King, B. P. DiMento, K. McNeill, C. J. Miller, W. L. Miller, B. M. Peake, S. A. Rusak, A. L. Rose, T. D. Waite, Aquat. Sci. 2012, 74, 683.

[26] a) P. L. Brezonik, J. Fulkerson-Brekken, Environ. Sci. Technol. 1998, 32, 3004; b) W. R. Haag, J. Hoigne, Chemosphere 1985, 14, 1659; c) R. G. Zepp, J. Hoigne, H. Bader, Environ. Sci. Technol. 1987, 21, 443.
[27] S. E. Page, W. A. Arnold, K. McNeill, Environ. Sci. Technol. 2011, 45, 2818.

[28] a) I. Dalle-Donne, G. Aldini, M. Carini, R. Colombo, R. Rossi, A. Milzani, J. Cell. Mol. Med. 2006, 10, 389; b) P. Morgan, E. Pattison, M. J. Davis, Free Radical Biol. Med. 2012, 52, 328.

[29] N. J. Turro, in 'Modern Molecular Photochemistry', University Science Books, Menlo Park, CA, 1978.

[30] P. B. Merkel, D. R. Kearns, Chem. Phys. Lett. 1971, 12,120 .

[31] a) C. Shao, W. J. Copper, D. R. S. Lean, in 'Aquatic and Surface Photochemistry', Ed. G. R. Helz, R. G. Zepp, D. G. Crosby, CRC Press: Boca Raton, 1994, p 215; b) L. Y. Wick, K. McNeill, M. Rojo, E. Medilanski, P. M. Gschwend, Environ. Sci. Technol. 2000, 34, 4354; c) C. J. M. Wolff, M. T. H. Halmans, H. B. Vanderheijde, Chemosphere 1981, 10, 59; d) R. G. Zepp, N. L. Wolfe, G. L. Baughman, R. C. Hollis, Nature 1977, 267, 421.

[32] a) S. G. Bertolotti, N. A. Garcia, G. A. Arguello, J. Photochem. Photobiol., B 1991, 10, 57; b) K. Inoue, T. Matsuura, I. Saito, Bull. Chem. Soc. Jpn. 1982, 55, 2959; c) G. Jori, G. Galiazzo, A. Marzotto, E. Scoffone, Biochim. Biophys. Acta 1968, 154, 1; d) S. Miskoski, N. A. Garcia, Photochem. Photobiol. 1993, 57, 447; e) M. C. Palumbo, N. A. Garcia, G. A. Arguello, J. Photochem. Photobiol., B 1990, 7, 33; f) P. K. Sysak, C. S. Foote, T. Y. Ching, Photochem. Photobiol. 1977, 26, 19; g) M. Tomita, M. Irie, T. Ukita, Biochemistry 1969, 8,5149 .

[33] C. Sonntag, H. P. Schuchmann, Angew. Chem., Int. Ed. 1991, 38, 1229

[34] a) L. E. Richard, B. M. Peake, S. A. Rusak, W. J. Cooper, D. J. Burritt, Environ. Chem. 2007, 4, 49; b) Y. Shaked, R. Harris, N. Klein-Kedem, Environ. Sci. Technol. 2010, 44, 3238.

[35] W. J. Cooper, R. G. Zika, R. G. Petasne, Environ. Sci. Technol. 1988, 22, 1156.

[36] S. Canonica, Chimia 2007, 60, 641.

[37] R. G. Zepp, P. F. Schlotzhauer, R. M. Sink, Environ. Sci. Technol. 1985, 19, 74.

[38] S. Canonica, B. Hellrung, J. Wirz, J. Phys. Chem. A 2000, 104, 1226.

[39] C. K. Remucal, K. McNeill, Environ. Sci. Technol. 2011, 45, 5230.

[40] J. Kim, M. E. Rodriguez, M. Guo, M. E. Kenney, N. L. Oleinick, V. E. Anderson, Free Radical Biol. Med. 2008, 44, 1700.

[41] R. A. Lundeen, K. McNeill, Environ. Sci. Technol. 2013, 47, 14215

[42] a) S. M. Henrichs, S. F. Sugai, Geochim. Cosmochim. Acta 1993, 57, 823; b) P.-H. Hsu, P. G. Hatcher, Geochim. Cosmochim. Acta 2005, 69, 4521; c) P.-H. Hsu, P. G. Hatcher, Org. Geochem. 2006, 37, 1694; d) M. Sander, J. E. Tomaszewski, M. Madliger, R. P. Schwarzenbach, Environ. Sci. Technol. 2012, 46, 9923; e) J. E. Tomaszewski, M. Madliger, J. A. Pedersen, R. P. Schwarzenbach, M. Sander, Environ. Sci. Technol. 2012, 46, 9932.

[43] a) M. Grandbois, D. Latch, K. McNeill, Environ. Sci. Technol. 2008, 42, 9184; b) D. E. Latch, K. McNeill, Science 2006, 311, 1743.

[44] T. Kohn, M. Grandbois, K. McNeill, K. L. Nelson, Environ. Sci. Technol. 2007, 41, 4626.

[45] J. P. Amend, E. L. Shock, Science 1998, 281, 1659.

[46] C. K. Mathews, K. E. Van Holde, in 'Biochemistry', Benjamin-Cummings Publishing Co., Redwood City, CA, 1990.

[47] a) R. A. Daumas, Mar. Chem. 1976, 4, 225; b) K. Mopper, P. Lindroth, Limnol. Oceanogr. 1982, 27, 336; c) J. P. Riley, D. A. Segar, J. Mar. Biol. Ass. U.K. 1970, 50, 713.

[48] G. J. Bartlett, C. T. Porter, N. Borkakoti, J. M. Thornton, J. Mol. Biol. 2002, 324, 105. 